"New insights into gene delivery to human neuronal precursor NT2 cells: a comparative study between lipoplexes, nioplexes and polyplexes" Agirre, M., Ojeda, E., Zarate, J., Puras, G., Grijalvo, S., Eritja, R., García del Caño, G., Barrondo, S., González-Burguera, I., López de Jesús, M., Sallés, J., Pedraz, J.L. Mol. Pharm., 12(11), 4056-4066 (2015).

doi: 10.1021/acs.molpharmaceut.5b00496

\title{
New insights into gene delivery to human neuronal precursor NT2 cells: a comparative study between lipoplexes, nioplexes and polyplexes
}

Mireia Agirre ${ }^{\text {a,b }}$, Edilberto Ojeda ${ }^{\text {a,b }}$, Jon Zarate ${ }^{\text {a,b }}$, Gustavo Puras ${ }^{\text {a,b }}$, Santiago Grijalvo b,c , Ramón Eritja ${ }^{\text {b,c }}$, Gontzal García del Caño ${ }^{\text {d }}$, Sergio Barrondo ${ }^{\text {e,f }}$, Imanol GonzálezBurguera $^{\text {e }}$, Maider López de Jesús ${ }^{\text {e,f }}$, Joan Sallés ${ }^{\text {e,f }}$, José Luis Pedraz ${ }^{\text {a,b,* }}$

a NanoBioCel Group, University of the Basque Country (UPV/EHU), Vitoria-Gasteiz, Spain

b Networking Research Centre of Bioengineering, Biomaterials and Nanomedicine (CIBER-BBN), Spain

${ }^{c}$ Institute of Advanced Chemistry of Catalonia, IQAC-CSIC, Barcelona, Spain

${ }^{d}$ Department of Neurosciences, Faculty of Pharmacy, University of the Basque Country (UPV/EHU)

${ }^{\mathrm{e}}$ Department of Pharmacology, Faculty of Pharmacy, University of the Basque Country (UPV/EHU)

${ }^{\mathrm{f}}$ Centro de Investigación Biomédica en Red de Salud Mental (CIBERSAM, Spain)

*Corresponding author: Jose Luis Pedraz, Ph.D. Laboratory of Pharmacy and Pharmaceutical Technology, Faculty of Pharmacy, University of the Basque Country, 01006, Vitoria-Gasteiz, Spain. E-mail address: joseluis.pedraz@ehu.es. Phone: + (34)945013091. Fax number: + (34)-945013040 


\begin{abstract}
The transfection of human NTera2/D1 teratocarcinoma-derived cell line (or NT2 cells) represents a promising strategy for the delivery of exogenous proteins or biological agents into the central nervous system (CNS). The development of suitable non-viral vectors with high transfection efficiencies requires a profound knowledge of the whole transfection process. In this work, we elaborated and characterized in terms of size and zeta potential three different non-viral vectors: lipoplexes (144 nm; -29.13 mV), nioplexes $(142.5 \mathrm{~nm} ;+35.4 \mathrm{mV})$ and polyplexes $(294.8 \mathrm{~nm} ;+15.1 \mathrm{mV})$. We compared the transfection efficiency, cellular uptake and intracellular trafficking of the three vectors in NT2 cells line. Lipoplexes exhibited the highest percentages of EGFP positive cells. The values obtained with polyplexes were lower compared to lipoplexes but higher than the percentages obtained with nioplexes. Cellular uptake results had a clear correlation respect to the corresponding transfection efficiencies. Regarding the endocytosis mechanism, lipoplexes enter in the cell, mainly, via clathrin-mediated endocytosis (CME) while polyplexes via caveolae-mediated endocytosis (CvME). Nioplexes were discarded for this experiment due to their low cellular uptake. By simulating an artificial endosome, we demonstrated that the vectors were able to release the DNA cargo once inside the late endosome. The data collected from this assay showed that at $6 \mathrm{~h}$, the genetic material carried by polyplexes was still located in the late endosome, while DNA carried by lipoplexes was already in the nucleus. This result indicates a faster intracellular traffic of the lipid-based vectors. Overall, our work gives new insights into the transfection process of NT2 cells by different non-viral vectors as a first step in the development of ex-vivo gene therapy platform.
\end{abstract}

Key words: non-viral vectors, transfection, endocytosis, pCMS-EGFP, NTera2/D1 cells 


\section{INTRODUCTION}

Cell therapy is a field that moves rapidly with new cell lines and tissue-engineered constructs developed globally every year. The human NTera2/D1 teratocarcinomaderived cell line (or NT2 cells) can be differentiated into well-characterized populations of neuron-like cells (or NT2-N) that engraft and mature when are transplanted into the adult central nervous system (CNS) of rodents and humans ${ }^{1-7}$. Moreover, human transplantation studies in the brain of stroke patients demonstrated a lack of tumorigenicity of these cells ${ }^{6,8}$. On the other hand, the NT2 cells can be used as cellular vehicles with glioma tropism ${ }^{9}$, adding a human cell-based delivery vehicle for clinical glioblastoma therapy, as it was similarly demonstrated for neural stem cells in animal models ${ }^{10,11}$. Although these features suggest that NT2 cells would be an excellent platform for ex vivo gene therapy in the $\mathrm{CNS}^{3,7,9,12,13}$, the use of non-viral strategies for gene transfer has been scarce ${ }^{14,15}$.

In the last decade, cationic lipid-mediated ${ }^{16}$ and cationic polymer-mediated non-viral gene delivery ${ }^{17}$ methods have become useful tools for cellular transfection. Although gene therapy is still dominated by viral vectors, which present higher transfection efficiencies compared to non-viral gene delivery systems, safety issues such as immunogenicity and mutagenicity hinder their clinical applications ${ }^{18-20}$. At this point, non-viral gene delivery has been the subject of increasing attention due to its relative safety, simple use and easy handling compared to viral vectors ${ }^{21,22}$. Among lipid based non-viral vectors, liposomes are the most widely used carriers for in vitro and in vivo gene delivery ${ }^{23}$. Lipofectamine 2000 is a commercialized cationic liposome based reagent, which has been extensively used for in vitro gene delivery purposes due to its high transfection efficiency ${ }^{24}$. In addition to liposomes, niosomes (non-ionic surfactant vesicles) have also gained interest as an alternative to liposomes due to their similar structure. Although the use of these structures has been mainly restricted to drug delivery, our research group has recently obtained some promising results that suggest the possible use of cationic niosomes as non-viral vectors for gene delivery ${ }^{25,26}$. Finally, among cationic 
polymers, chitosan is an appropriate candidate for non-viral gene delivery due to its biocompatibility, biodegradability and low cost ${ }^{27}$. Our research group has been working with ultrapure oligochitosan (UOC) obtaining promising results ${ }^{28,29}$. The non-viral carriers (liposomes, niosomes or polymers) are typically cationic in nature and electrostatically interact with negatively charged DNA molecules forming the so-called lipoplexes, nioplexes and polyplexes, respectively.

Regardless the gene carrier, it is well known that the final gene expression will be highly influenced by the uptake of the non-viral vector, the internalization pathway and, their ability to escape from the endosomes and import the genetic material into the nucleus ${ }^{30}$. At the same time, the internalization route of the vectors will depend on their composition and physicochemical characteristics, such as size, polydispersity, surface charge and morphology ${ }^{31}$. Thus, it is essential to study, specifically, the uptake and intracellular trafficking of each selected non-viral vector, to understand their possible limitations and improve their design.

Therefore, this work was intended to carry out a comparative study of three types of nonviral vectors in human neuronal precursor NT2 cell line. Specifically, we compared lipoplexes based on the commercialized Lipofectamine 2000; nioplexes based on a previously described novel noisome formulation; and polyplexes based on UOCs. For this purpose, the vectors were characterized in terms of size, polydispersity index (PDI) and surface charge. The percentage of transfected cells, mean fluorescent intensity (MFI) and cell viability were analyzed by flow cytometry. Additionally, the expression of the enhanced green fluorescent protein (EGFP) was analyzed by Western Blot. To further explain the differences in the transfection efficiencies that among the three formulations, we performed qualitative and quantitative cellular uptake studies, by confocal microscopy and flow cytometry, respectively, using $\mathrm{Cy} 3$ or FITC labeled plasmids. The endocytosis pathways of the studied vectors were determined by colocalization assays and quantified by the Mander's overlap coefficient. Finally, the endosomal escape was analyzed by simulating the interaction of the vectors with anionic micelles, analogues of endosomal compartment.

\section{MATERIAL AND METHODS}




\section{Propagation of pCMS-EGFP}

The pCMS-EGFP reporter plasmid was purchased from Plasmid Factory (Bielefeld Germany) and was propagated in Escherichia coli DH5- $\alpha$ and purified using the Qiagen endotoxin-free plasmid purification Maxi prep kit (Qiagen, Santa Clarita, CA, USA) according to the manufacturer's instructions. The concentration of pDNA was quantified by measuring the absorbance at $260 \mathrm{~nm}$ using a NanoDrop ${ }^{\circledR}$ (ND-1000 spectrophotometer, Thermo Fisher Scientific Inc., Denver, USA). The purity of the plasmid was verified by agarose gel electrophoresis in Tris-borate-EDTA buffer, $\mathrm{pH} 8.0$ (TBE buffer). DNA bands were detected using GelRed ${ }^{\mathrm{TM}}$ (Biotium, Hayward, California, USA) and images were observed with a ChemiDoc ${ }^{\mathrm{TM}}$ MP imaging system (Bio-Rad, USA).

\section{Niosomes elaboration}

The cationic lipid 2,3-di(tetradecyloxy)propan-1-amine used for niosome elaboration was synthesized as previously described by Grijalvo et al. ${ }^{32}$. Niosomes were prepared by the oil in water $(\mathrm{o} / \mathrm{w})$ emulsification method ${ }^{26} .5 \mathrm{mg}$ of the cationic lipid were gently ground with $20 \mu \mathrm{l}$ of squalene. Then, $1 \mathrm{ml}$ of dichloromethane was added and emulsified with $5 \mathrm{ml}$ of an aqueous phase containing the non-ionic surfactant polysorbate $80(0.5 \%$, w/w). The emulsion was obtained by sonication (Branson Sonifier 250, Danbury) for $30 \mathrm{~s}$ at $50 \mathrm{~W}$. The organic solvent was removed from the emulsion by evaporation under magnetic agitation for three $h$. Upon dichloromethane evaporation, a dispersion containing the nanoparticles was formed by precipitation of the cationic nanoparticles in the aqueous medium. The final concentration of the cationic lipid in the niosome formulation was $1 \mathrm{mg} / \mathrm{ml}$.

\section{Preparation and characterization of the complexes}

Lipoplexes, nioplexes, and polyplexes were prepared by mixing at determinate weight/weight (w/w) ratios Lipofectamine 2000 (Invitrogen, Life Technologies, USA) solution, niosomes or UOC (Novafect O15 with a molecular weight of $5.7 \mathrm{KDa}$ and 97 $\%$ degree of deacetylation, purchased from NovaMatrix/FMC, Sandvika, Norway) solution with the pCMS-EGFP plasmid. (i) Lipoplexes were prepared at a Lipofectamine/DNA w/w ratio of $2: 1$ by mixing gently Lipofectamine solution $(1 \mathrm{mg} / \mathrm{ml})$ and pCMS-EGFP solution $(0.5 \mathrm{mg} / \mathrm{ml})$ (ii) Nioplexes were prepared at a fixed cationic lipid/DNA ratio 20:1 (w/w). (iii) For polyplexes preparation, UOC solution was 
dissolved in miliQ water to a final concentration of $2 \mathrm{mg} / \mathrm{ml}$. pCMS-EGFP solution was added under vortex mixing (15 s) to the chitosan solution at a final UOC/DNA w/w ratio of 13:1. In all cases, the formulations were incubated for 30 minutes at room temperature to allow the correct formation of the complexes.

The complexes were characterized in terms of size and zeta potential. The measurements were carried out as previously described by Ojeda et al. using a Zetasizer NanoZS (Malvern Instruments, UK) ${ }^{26}$. Briefly, $50 \mu 1$ of the complexes containing $0.625 \mu \mathrm{g}$ pCMS-EGFP were resuspended in $950 \mu \mathrm{l}$ of $\mathrm{NaCl} 0.1 \mathrm{mM}$. The particle size reported as hydrodynamic diameter was obtained by Dynamic Light Scattering, and the zeta potential was obtained by Laser Doppler Velocimetry. All measurements were carried out in triplicate.

\section{Cell culture and transfection protocol}

Human teratocarcinoma NTERA2/D1 (NT2) cells from the American Type Culture Collection (ATCC®, CRL-1973 ${ }^{\mathrm{TM}}$ ) were maintained in complete medium: Dulbecco's Modified Eagle medium (DMEM®, ATCC 30-2002 ${ }^{\mathrm{TM}}$ ), supplemented with $10 \%$ fetal bovine serum (FBS, Sigma-Aldrich, St Louis, MO, USA ) and antibiotics (100 U/mL penicillin and $100 \mu \mathrm{g} / \mathrm{mL}$ streptomycin, Gibco, Life Technologies S.A., Madrid, Spain), at $37^{\circ} \mathrm{C}$ under a humidified atmosphere containing $5 \% \mathrm{CO} 2$.

Before transfection, NT2 cells were seeded in 24 well plates at an initial density of $8 \times$ $10^{4}$ cells per well with $400 \mu \mathrm{l}$ complete medium and allowed to grow to $70-80 \%$ confluence. Then, the complete medium was replaced with serum-free Opti-MEM® (Gibco, Life Technologies S.A.), and the cells were exposed to the complexes at the corresponding w/w ratios (containing $1.25 \mu \mathrm{g}$ pCMS-EGFP per well) (Table 1). In the case of polyplexes, Opti-MEM ${ }^{\circledR}$ containing $270 \mathrm{mM}$ mannitol was used to obtain a final isotonic medium. Also, the $\mathrm{pH}$ was adjusted to 7 with $\mathrm{HCl} 0.1 \mathrm{~N}$, as it has been previously described the improved transfection with this kind of formulations at slightly acidic $\mathrm{pH}$ values. After four hours of incubation at $37^{\circ} \mathrm{C}$, the complexes were removed and replaced with $380 \mu \mathrm{l}$ complete medium and were allowed to grow until the analysis time. 


\begin{tabular}{cccc}
\hline Formulation & Main component & $\begin{array}{c}\text { w/w } \\
\text { ratio }\end{array}$ & $\begin{array}{c}\text { DNA } \\
\text { quantity }(\boldsymbol{\mu g})\end{array}$ \\
\hline Lipoplexes & Lipofectamine 2000 reagent & $2: 1$ & 1.25 \\
Nioplexes & 2,3-di(tetradecyloxy)propan-1-amine & $20: 1$ & 1.25 \\
Polyplexes & Novafionic lipid & $13: 1$ & 1.25 \\
\hline
\end{tabular}

Table 1: Summary of the main components, w/w ratios and DNA quantities employed for the elaboration of the three formulations.

\section{Analysis of EGFP expression and cell viability}

Qualitative expression of EGFP was analyzed using an inverted microscope equipped with an attachment for fluorescent observation (model EclipseTE2000-S, Nikon). Flow cytometry analysis was conducted using a FACSCalibur system flow cytometer (Becton Dickinson Biosciences, San Jose, USA), in order to quantify the percentage of EGFP positive cells and the mean fluorescent intensity (MFI). At the end of the incubation period, cells were detached with $200 \mu \mathrm{l}$ of trypsin/EDTA and, $400 \mu \mathrm{l}$ of complete medium were added to inhibit trypsin activity. Then, cells were transferred to specific flow cytometer tubes to quantify EGFP expression. For cell viability measurements, 5 $\mu l$ of the BD-via probe reagent (7-AAD) was added to each sample. Transfection efficiency was expressed as the percentage of EGFP positive cells at $525 \mathrm{~nm}$ (FL1), and cell viability was expressed as the percentage of 7-AAD negative cells at $650 \mathrm{~nm}$ (FL3). Control samples (non-transfected cells) were displayed on a dot plot of forward scatter against side scatter to establish a collection gate. For each sample, 10,000 events were collected.

In addition, EGFP protein expression was analyzed by Western Blot of whole cell homogenates. Thus, expression was analyzed semiquantitatively at 24,48 and $72 \mathrm{~h}$ after transfection with the different reagents. For each independent analysis, cells from 3 wells per condition were lysed and pooled in $300 \mu \mathrm{l}$ lysis buffer: Tris- $\mathrm{HCl}(50 \mathrm{mM}$, pH 
7.4), $150 \mathrm{mM} \mathrm{NaCl}, 1 \%$ Igepal (Sigma-Aldrich), 0.5\% sodium deoxycholate (SigmaAldrich), 0.1\% sodium dodecyl sulfate (SDS), $2.5 \mathrm{mM} \mathrm{CHAPS} \mathrm{(Sigma-Aldrich)} \mathrm{and}$ protease inhibitor cocktail (50 $\mu \mathrm{l} / \mathrm{mg}$ protein; Sigma-Aldrich). Solubilized proteins were collected from supernatants of samples after centrifugation at 40,000 x g for $5 \mathrm{~min}$ at 4 $\left.{ }^{\circ} \mathrm{C}\right)$. Protein concentrations were determined with the BCA protein quantification kit (Abcam, Cambridge, UK; BD Transduction Laboratories, San Diego CA, USA). Increasing amounts $(4,6,8,10 \mu \mathrm{g})$ of proteins from cells $24 \mathrm{~h}$ after transfection with Lipofectamine 2000 and $10 \mu \mathrm{g}$ of samples from the rest of conditions were run in parallel and resolved by electrophoresis on SDS-polyacrylamide (SDS-PAGE) 10\% gels. The uppermost part of the gel containing proteins above the $75 \mathrm{kDa}$ standard was separated and stained with Coomassie Blue for a protein load control. The rest of proteins were transferred to polyvinylidene fluoride (PVDF) membranes (Amersham Bioscience, Buckinghamshire, UK). Blots were blocked in 5\% non-fat dry milk/phosphate buffered saline containing $0.5 \%$ BSA and $0.2 \%$ Tween (blocking buffer) for $1 \mathrm{~h}$, and incubated with rabbit polyclonal anti-GFP antibody (Invitrogen, Ref. A11122) 1:2000 diluted in blocking buffer. After extensive washing, the PVDF membranes were incubated with horseradish peroxidase-conjugated secondary antibodies diluted to $1: 10,000$ in blocking buffer for $2 \mathrm{~h}$ at room temperature. Immunoreactive bands were detected with ECL reagent according to the manufacturer's instructions (Amersham Bioscience, Buckinghamshire, UK). EGFP-specific immunoreactive bands were acquired from four independent experiments using an ImageQuant 350 imager (GE Healthcare, Madrid, Spain) and quantified by densitometry using ImageJ image analysis software (ImageJ, NIH, Bethesda, MD, USA). Optical density (OD) values from bands corresponding to increasing protein amounts from Lipofectamine 2000-transfected at $24 \mathrm{~h}$ post-transfection were used for linear regression analysis. Thus, we obtained a linear regression equation, which allowed us to calculate the fold change of EGFP immunoreactivity for each condition (transfection reagent and post-transfection time) compared to the samples from cells at $24 \mathrm{~h}$ after transfection with Lipofectamine 2000.

\section{Cellular uptake assays}

NT2 cells were cultured and seeded as for transfection experiments. Then, the regular growth media was removed from the wells and the cells were exposed to the complexes containing $1.25 \mu \mathrm{g}$ of the pCMS-EGFP labelled with fluorescein isothiocyanate (FITC) 
(DareBio, Spain) or Cy3 (Mirus Bio Corporation, Madison, WI). After $1 \mathrm{~h}$ or $4 \mathrm{~h}$ of at 37 ${ }^{\circ} \mathrm{C}$, the transfection medium was removed and cells were washed with PBS and fixed with formaldehyde $4 \%$ for the quantitative and qualitative analysis, by flow cytometry and confocal laser scanning microscopy (CLSM), respectively. Each formulation was analyzed by triplicate.

Cells were analyzed after $1 \mathrm{~h}$ or $4 \mathrm{~h}$ of incubation by flow cytometry at $525 \mathrm{~nm}$ (FL1) after detachment from the wells. 10,000 events were collected for each sample. Cellular uptake data was expressed as the \% of FITC positive cells. For the qualitative study, cells were seeded on coverslips containing plates and treated with the vectors (containing Cy3 labelled DNA). After $4 \mathrm{~h}$ of incubation, cells were stained with Phalloidin AlexaFluor-488 and preparations were mounted on Dapi Fluoromount-G (Southern Biotech) and then, images were obtained with an Olympus Fluoview FV500 microscope. CLSM images were captured in the General Service of Analytical Microscopy and High Resolution in Biomedicine of the University of the Basque Country (UPV/EHU, Bizkaia, Spain).

\section{Colocalization assays}

The endocytic processes involved in the internalization of the complexes were analyzed by colocalization assays. NT2 cells were seeded on coverslips (as described for transfection protocol) and co-incubated with the complexes (containing the FITC labeled pCMS-EGFP) and different endocytosis fluorescent markers: AlexaFluor546Transferrin $(50 \mu \mathrm{g} / \mathrm{ml})$, AlexaFluor555-Cholera toxin $(10 \mu \mathrm{g} / \mathrm{ml})$ or Lysotracker $(140$ $\mathrm{nM}$ ), which are markers for clathrin-mediated endocytosis (CME), caveolae/raftmediated endocytosis (CvME) and late endosomal compartment, respectively. After 3 hours of incubation with the complexes, the markers were added to the cells, and they were incubated one more hour. Then, the cells were fixed with formaldehyde $4 \%$ and mounted on DAPI fluoromont $G$ for their posterior examination by CLSM. Colocalization of the green and red signal was analyzed by ImageJ software and quantified by the Mander's coefficient ${ }^{33}$.

\section{Vulnerability assay of the complexes in the late endosome}


As an analogue of the endosomal compartment, anionic micelles based on phosphatidylserine (PS) (Sigma-Aldrich, Spain) were prepared, as described previously

${ }^{34}$. PS was dissolved in chloroform at $1.6 \mathrm{mM}$ and left under magnetic stirring until the solvent was completely evaporated. Phosphate buffer was added to the dried sample, and a dispersed solution was obtained by sonication (Branson Sonifier 250, Danbury). PS micelles and the complexes were incubated at a w/w ratio of 1:50 (pCMS-EGFP: PS) for1 hour. After that, the amount of the released DNA from each complex was determined by agarose gel electrophoresis. Naked plasmid or complexes (containing 205 ng pCMS-EGFP) were loaded onto a $0.8 \%$ agarose gel and exposed for 30 min to 100 V. DNA bands were stained with GelRed ${ }^{\mathrm{TM}}$ (Biotium, Hayward, California, USA) and images were observed with a ChemiDocTM MP Imaging System (BioRad, Madrid, Spain) and analyzed with Image LabTM software (Bio-Rad, Madrid, Spain).

\section{Statistical analysis}

All data are expressed as mean $\pm \mathrm{SD}, \mathrm{n}=3$. The Kruskal-Wallis Test and Dunn's Multiple Comparison post-test were applied with InStat programme (GraphPad Software, San Diego, CA, USA) to make statistical comparisons. Differences were considered statistically significant when $P<0.05$.

\section{RESULTS}

\section{Size, PDI and zeta potential of the complexes}

Fig. 1 summarizes the characterization of the complexes. While lipoplexes and nioplexes presented a particle size around $140 \mathrm{~nm}$ with low PDI (0.21), polyplexes showed bigger size (294 nm) and PDI (0.44) (Fig. 1A). The higher polydispersity of the polyplexes can also be observed in the size distribution curve (Fig. 1B). Regarding the surface charge, it varied from negative to positive values depending on the vector. Lipoplexes were negatively charged $(-29.13 \mathrm{mV})$ while nioplexes and polyplexes had a positive zeta potential, $+35.4 \mathrm{mV}$ and $+15.1 \mathrm{mV}$, respectively (Fig. 1A). 
A

\begin{tabular}{lccc}
\hline & Size $(\mathrm{nm})$ & pdi & zeta ptential $(\mathrm{mV})$ \\
\hline Lipoplexes & $144.1 \pm 6.3$ & $0.21 \pm 0.04$ & $-29.13 \pm 1.43$ \\
Nioplexes & $142.5 \pm 0.64$ & $0.21 \pm 0.04$ & $35.4 \pm 0.7$ \\
Polyplexes & $294.8 \pm 23.36$ & $0.44 \pm 0.04$ & $15.1 \pm 3.05$ \\
\hline
\end{tabular}

B

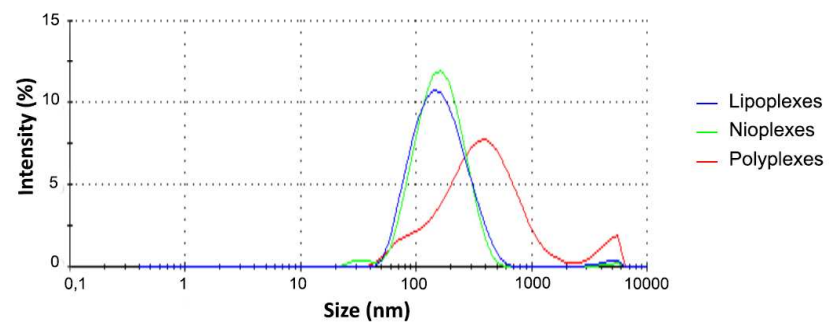

Figure 1. Characterization of the complexes. (A) Size, PDI, and zeta potential values. Each value represents the mean \pm standard deviation of three measurements. (B) Size distribution curve of the complexes.

\section{NT2 cell viability and EGFP expression}

The percentage of viability was determined by flow cytometry at 24,48 and $72 \mathrm{~h}$ postincubation. Cell viability was above $70 \%$ in the three tested formulations at all analyzed times (Fig. 2), showing minimal differences among the formulations in all tested times.

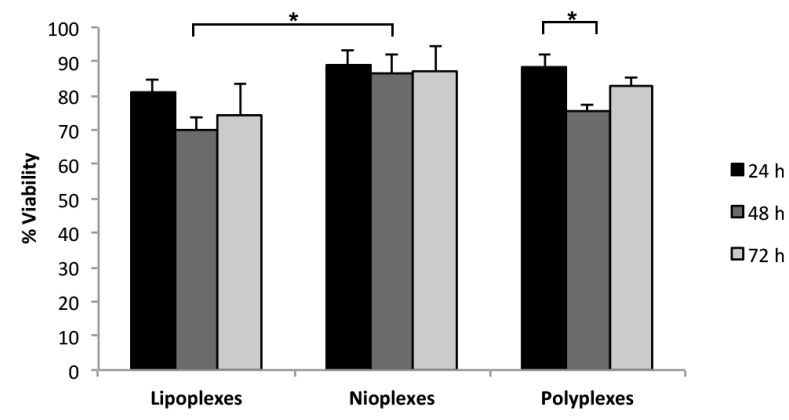

Figure 2. Cell viability of NT2 cells at 24, 48 and 72 hours after the treatment with the complexes. Error bars represent $\pm \mathrm{SD}(\mathrm{n}=3) . * P<0.05$

The percentage of EGFP positive live cells at 24, 48 and 72 hours post-transfection was analyzed by flow cytometry (Fig. 3A). No statistical differences were observed among the tested times except for lipoplexes; in this case, a significant decrease was observed 
at $72 \mathrm{~h}(37 \%)$ compared to $24 \mathrm{~h}(22 \%)$. Among the three formulations, lipoplexes exhibited the highest transfection percentages (up to $35 \%$ at $24 \mathrm{~h}$ ), and nioplexes the lowest (5\%), while polyplexes were able to transfect almost $20 \%$ of the cells. Microscopic photographs (Fig. 3B) corroborated these results, as almost no EGFP positive cells were observed after their transfection with nioplexes (Fig. 3 B6). A welldefined cell population can be found in flow cytometry dot plots (FSC vs. SSC) in all cases (Fig. 3 C1, C3, C5, and C7). In FL1 (GFP) vs. FL3 (7-AAD) dots plots, the higher transfection efficiency of lipoplexes (Fig.3 C4) and polyplexes (Fig. $3 \mathrm{C} 8$ ) compared to nioplexes (Fig. 3 C6) and the non-treated cells (Fig. 3 C2) is explicitly represented.
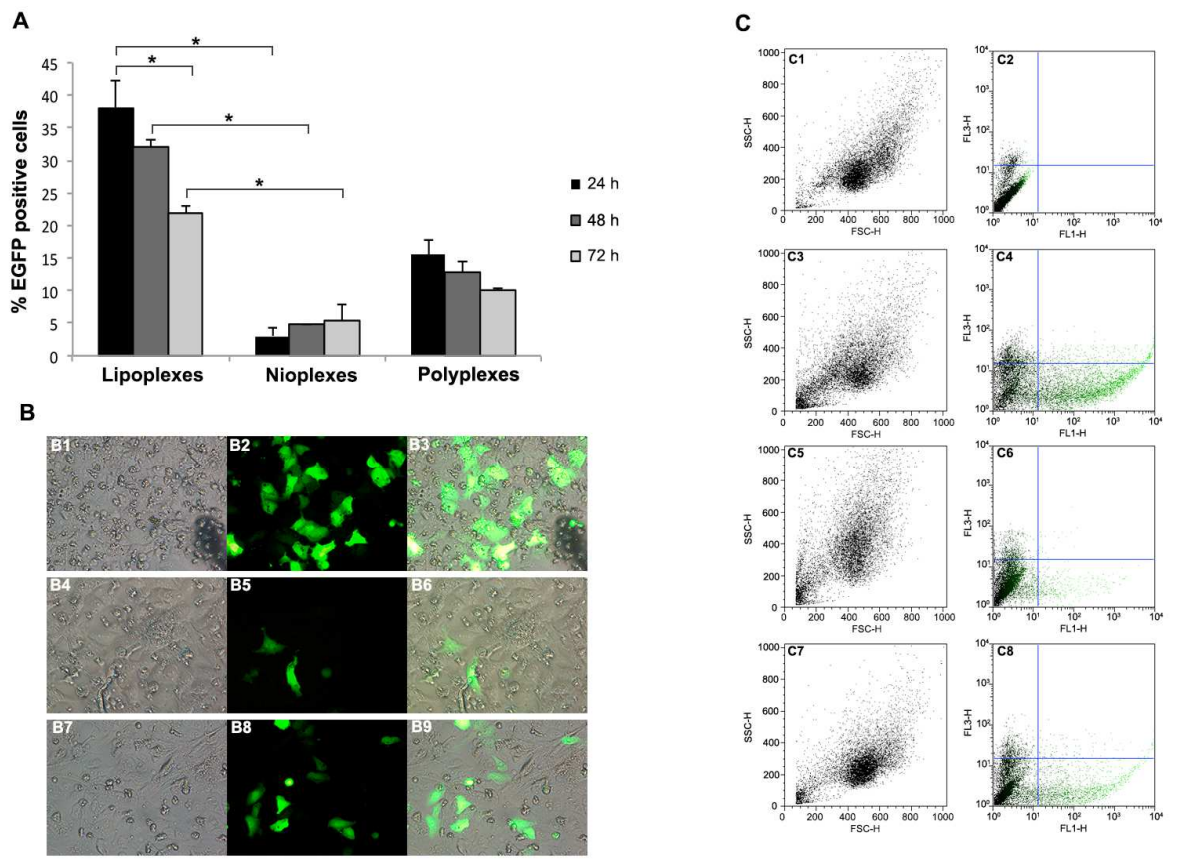

Figure 3. Transfection efficiency of the three tested complexes. (A) Bar graphs showing the percentage of EGFP positive live cells at 24, 48 and 72 hours post-transfection. Error bars represent \pm SD $(\mathrm{n}=3) * P<$ 0.05. (B) Microscope photographs of NT2 cells at $48 \mathrm{~h}$ post-transfection. (B1, B4, B7) phase contrast images, (B2, B5, B8) fluorescent images and, (B3, B6, B9) overlay images of cells transfected with (B1, B2, B3) lipoplexes, (B4, B5, B6) nioplexes and (B7, B8, B9) polyplexes. (C) Flow cytometry dot plots representing $(\mathrm{C} 1, \mathrm{C} 2, \mathrm{C} 3, \mathrm{C} 5, \mathrm{C} 7) \mathrm{FSC}$ vs $\mathrm{SSC}$ and $(\mathrm{C} 2, \mathrm{C} 3, \mathrm{C} 4, \mathrm{C} 6, \mathrm{C} 8)$ FL1 vs FL3 of NT2 cells treated with (C1, C2) negative control, (C3, C4) lipoplexes, (C5, C6) nioplexes and (C7, C8) polyplexes, 48 hours post transfection. FL1 channel corresponds to GFP and FL3 channel corresponds to 7-AAD.

In order to show the production of EGFP in the cells, MFI of the transfected cells was calculated (Fig. 4A) and Western Blot analysis of EGFP expression was performed (Fig. 4B). Both, MFI measurements and densitometric analysis of EGFP 
immunostaining revealed that lipoplexes and nioplexes exhibited the highest and the lowest MFI values, respectively. Interestingly, lipoplexes showed the highest MFI values, while nioplexes the lowest. Kruskal-Wallis test followed by Dunn's multiple comparisons revealed no statistical differences in MFI among the tested times except for polyplexes. In this case, a significant increase is observed at 48 hours compared to the previously studied time. In contrast, significant differences were found between the different formulations. Specifically, 24 and 48 hours after transfection, MFI values were significantly higher in lipoplexe- than in nioplexe-transfected cells and significant differences were also detected at 72 hours between nioplexe- and polyplexe-transfected cells (Fig. 4. A). In addition, Western blot analysis corroborated these results. As seen in Fig. 4B, barely detectable EGFP was produced after transfection with nioplexes. By contrast, a well-defined band appeared with lipoplexes and polyplexes, at all tested points. In agreement with MFI values, a more intense EGFP band was obtained with lipoplexes.
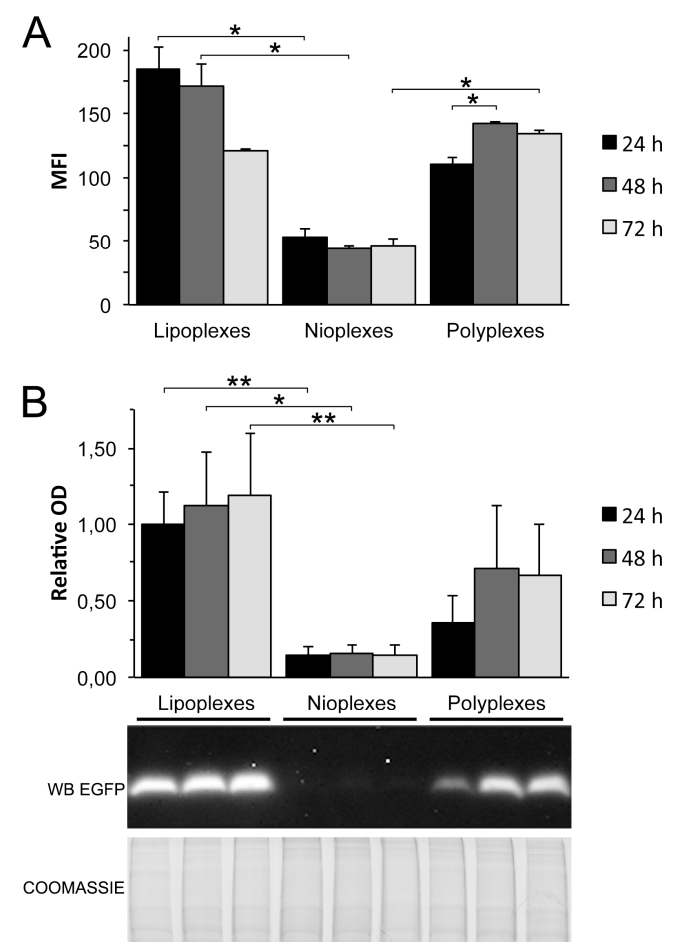

Figure 4. Expression of EGFP protein at 24, 48 and 72 hours post-transfection. (A) A bar graph showing MFI values for cells transfected with the different complexes. Error bars represent mean $\pm \mathrm{SD}(\mathrm{n}=3)$. (B) Bar graph depicts results of the semiquantitative analysis of EGFP protein expression by Western Blot. A representative Western Blot is shown below the bar graph. Error bars represent mean $\pm \mathrm{SD}(\mathrm{n}=4)$. Kruskal-Wallis test followed by Dunn's multiple comparison post-test. $* P<0.05, * * P<0.01$.

\section{Cellular uptake}


The flow cytometry analysis carried out with FITC-labelled pDNA complexes indicated that cellular uptake was clearly time dependent. The percentage of FITC positive cells increased along the time, from $50 \%$ (lipoplexes), almost no uptake (nioplexes) and 20 $\%$ (polyplexes) after $1 \mathrm{~h}$ of incubation, to $70 \%$ (lipoplexes), $10 \%$ (nioplexes) and $30 \%$ (polyplexes) after $4 \mathrm{~h}$ of incubation with the complexes (Fig. 5A). However, statistical differences were only observed between lipoplexes and nioplexes. In the flow cytometry histogram (Fig. 5B) the uptake of the complexes after four hours of incubation is observed: lipoplexes > polyplexes > nioplexes. Confocal microscope images supported the quantitative results (Fig. $5 \mathrm{C} 1, \mathrm{C} 2$, and $\mathrm{C} 3$ ).
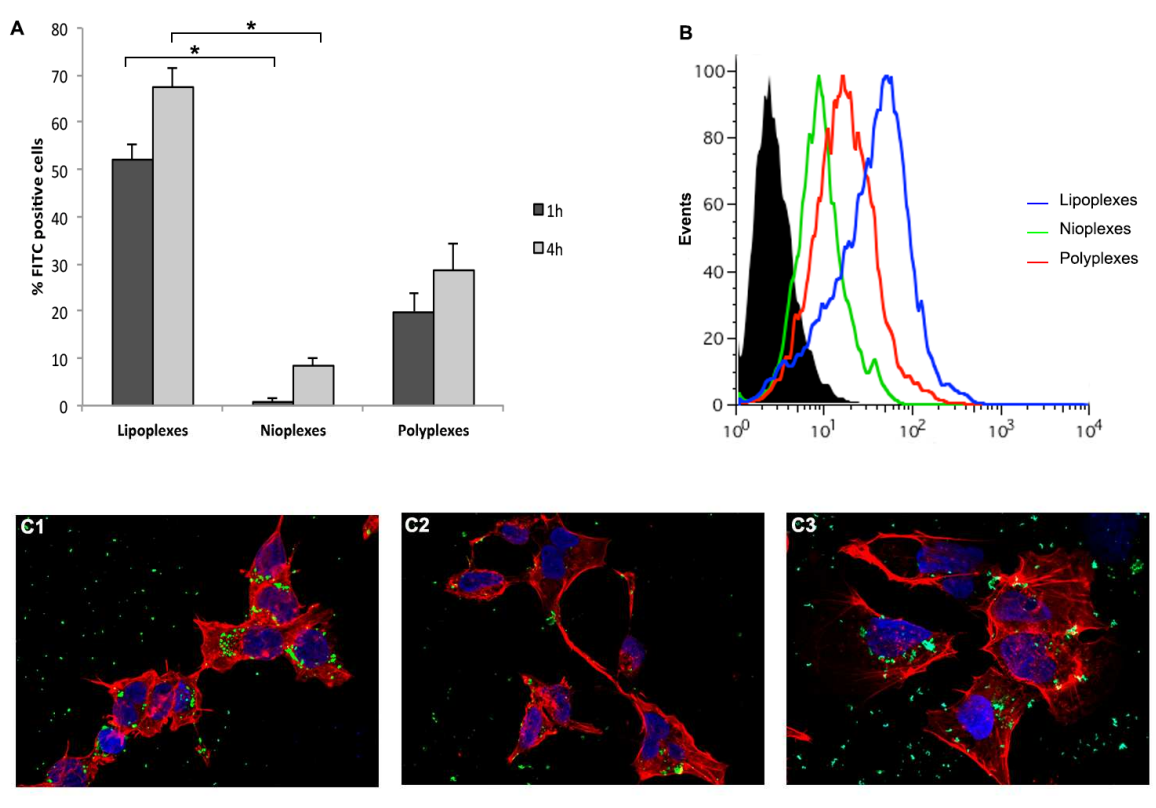

Figure 5. Cellular uptake of the complexes. (A) Bar graphs showing the percentage of FITC positive NT2 cells after the incubation for 1 hour or 4 hours with the complexes. Error bars represent \pm SD (n=3). $* P<$ 0.05. (B) Flow cytometry histograms representing the cellular uptake of the complexes (formed with FITC labelled plasmid DNA) after $4 \mathrm{~h}$ of incubation. Black filled curve represents untreated cells. (C) Merged images of NT2 cells four hours after the addition of (C1) lipoplexes, (C2) nipolexes and (C3) polyplexes. Images are at $63 \mathrm{X}$ magnification. Blue colouring shows cell nuclei stained with DAPI; red colouring shows F-actin stained with Phalloidin; green colouring shows Cy3 labelled plasmid DNA complexed with the corresponding non-viral vector.

\section{Cell uptake mechanisms}


The presence of CME and CvME pathways in NT2 cells was determined with specific markers of endocytic routes, Transferrin-Alexa Fluor and Cholera Toxin-Alexa Fluor, respectively. Flow cytometry histograms (Fig. 6 A1 and A2) illustrated that almost 100 $\%$ of NT2 cells were appropriately stained after the treatment with fluorescent markers. This data indicated that both CME and CvME are present in the studied cell line.

Fig. 6B illustrates the confocal images four hours after the co-treatment with the endocytosis markers (red) and lipoplexes /polyplexes (green). Due to the low cellular uptake of nioplexes, this formulation was discarded for uptake mechanism studies. Colocalization of red and green fluorescence showed visible yellow/orange punctate structures (Fig. 6B). In addition, we performed a quantitative analysis; the colocalization values were represented as the fraction of complexes colocalized with the fluorescently labelled endocytic structures, represented by the Mander's (M1) coefficient. The colocalization value of lipoplexes with Transferrin-Alexa Fluor (marker of CME pathway) was higher than the colocalization with Cholera toxin-AlexaFluor (marker of CvME pathway): Mander's overlap coefficients were 0.471 and 0.367 , respectively (Fig.6 B1 and B2). The overlap coefficients were superior for polyplexes, 0.576 with CME marker and 0.697 with CvME marker (Fig.6 B3 and B4). 


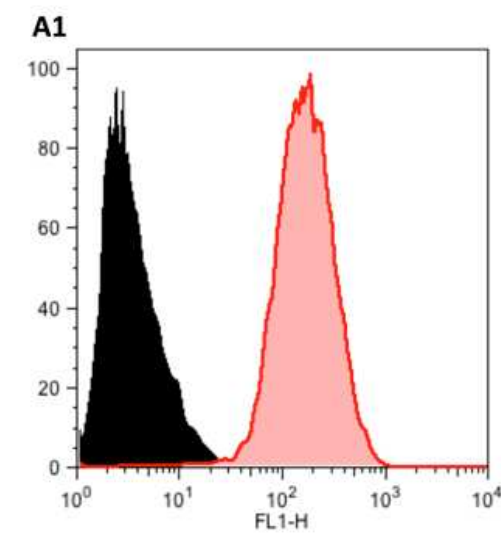

Clathrin-mediated endocytosis
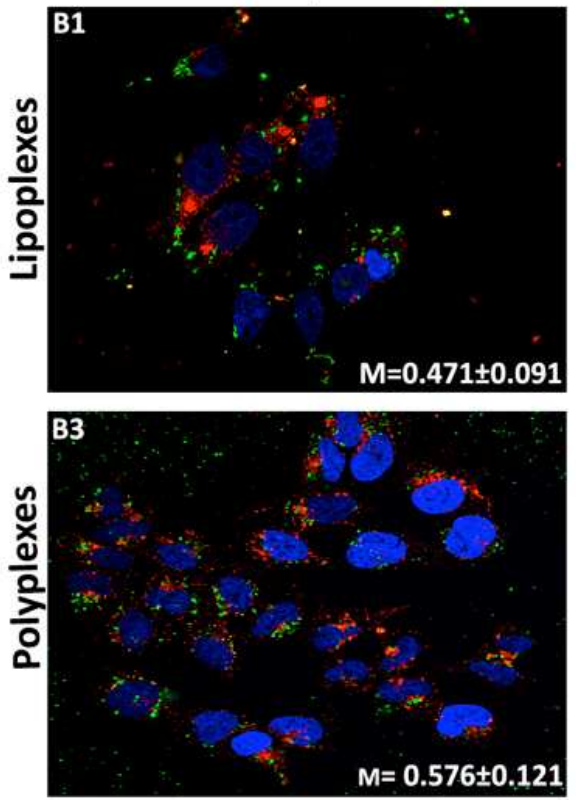

\section{A2}

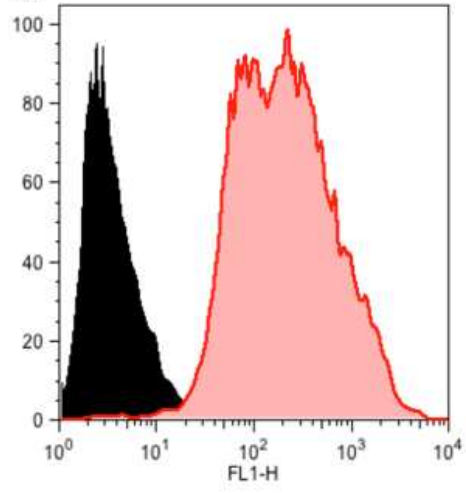

Caveolae-mediated endocytosis
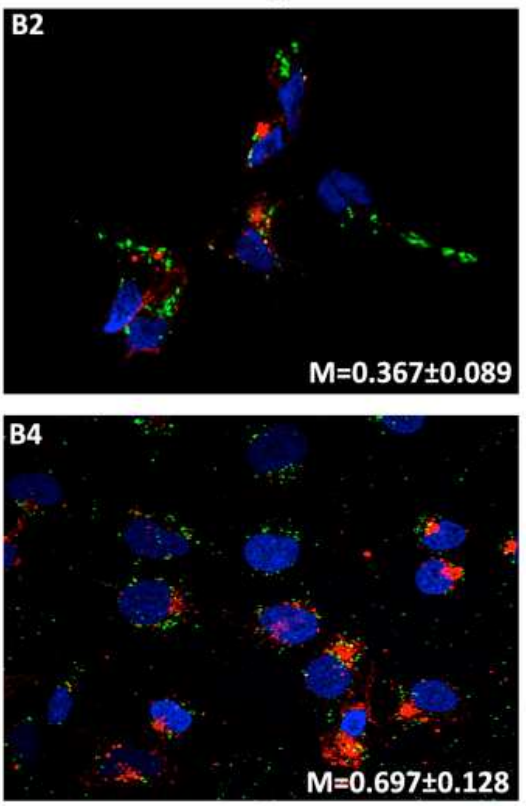

Figure 6. Endocytosis pathway of the complexes. (A) Flow cytometry histograms of cells treated with (A1) Transferrin-Alexa Fluor 488 at $50 \mu \mathrm{g} / \mathrm{ml}$ and (A2) Cholera toxin-Alexa Fluor 488 at $10 \mu \mathrm{g} / \mathrm{ml}$. Black filled curve represents untreated cells. (B) Colocalization of test complexes (formed with FITC labelled plasmid DNA) (green) with the specific markers of endocytic pathways (red): clathrin-mediated endocytosis (Alexa Fluor 546-Transferrin at $50 \mu \mathrm{g} / \mathrm{ml}$ ) and caveolae-mediated endocytosis (Alexa Fluor 555-cholera toxin at $10 \mu \mathrm{g} / \mathrm{ml}$ ). The images were taken after 4 hours of incubation with the test complexes. Images are at 63x magnification. Nuclei are stained with DAPI (blue). The presence of yellow colour represents the overlay of the endocytic pathway marker and the vectors. The colocalization values are given as the fraction of complexes colocalizing with fluorescently labelled endocytic structure, represented by Mander's (M1) coefficient. 


\section{Intracellular trafficking and endosomal escape}

The colocalization of the complexes with the late endosomes at 4 and 6 hours was visualized and quantified by labelling the endosomal compartment with a specific marker: Lysotracker (red colour). Colocalization of red and green fluorescence gave rise to visible yellow/orange punctate structures (Fig. 7A). The quantitative value was given as the Mander's overlap coefficient. The results showed that polyplexes were located mainly in the late endosome after 4 hours $(M=0.735)$, and remained at least until $6 \mathrm{~h}$ $(\mathrm{M}=0.764)$. The values with lipoplexes were lower at both times $(0.543$ at $4 \mathrm{~h}$ and 0.489 at 6 h). In Fig. $7 \mathrm{~A}$ we observed that at 6 hours, the DNA carried by lipoplexes was located in the nucleus, and even at 4 hours this was evident.

In order to evaluate whether the complexed DNA can be released from the endosomes, we examined the amount of released DNA after mixing the complexes with the previously elaborated PS micelles. The vesicles showed sizes of $170 \mathrm{~nm}$ and zeta potential of $-65 \mathrm{mV}$. As observed in the agarose gel (Fig. 7C), DNA was released from all the complexes after their incubation with PS micelles (Fig. 7B). Almost $80 \%$ of the total DNA was released from lipoplexes (lane 2); $40 \%$ from nioplexes (lane 3) and 30 $\%$ from polyplexes (4). The release of the DNA was lower without the previous incubation with the anionic micelles: $30 \%, 5 \%$ and $0 \%$ with lipoplexes (lane 5), nioplexes (lane 6) and polyplexes (lane 7), respectively.
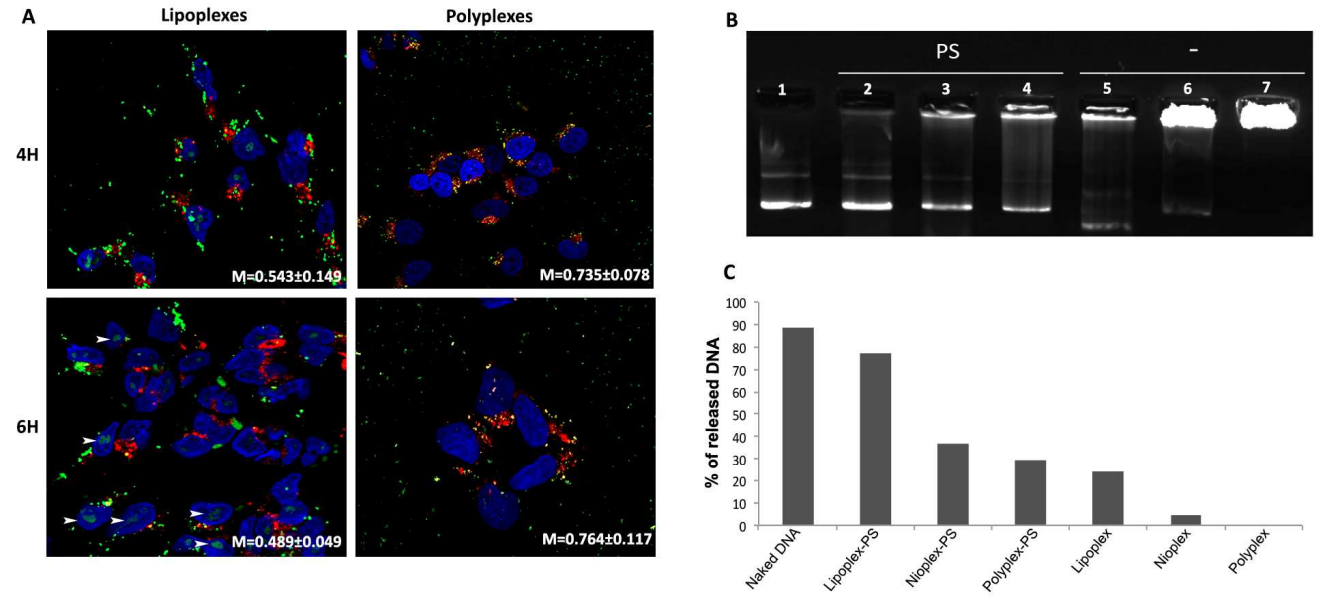

Figure 7. (A) Colocalization of test complexes (formed with FITC labelled plasmid DNA) (green) with Lysotracker Red-DND-99 that is a specific marker of the late endosome (red). The images were taken 
after 4 and 6 hours of incubation with the test complexes. Markers were added 1 hour prior to the end of the incubation time. Images are at $63 \mathrm{x}$ magnification. Nuclei are stained with DAPI (blue). Presence of yellow colour represents the overlay of the endocytic pathway marker and the vectors. The colocalization values are given as the fraction of complexes colocalizing with fluorescently labelled endocytic structure, represented by Mander's (M1) coefficient. (B) DNA release profiles measured with gel electrophoresis. Lane 1: naked DNA; lane 2: lipoplexes incubated with PS; lane 3: nioplexes incubated with PS; lane 4: polyplexes incubated with PS; lane 5: lipoplexes; lane 6: nioplexes; lane 7: polyplexes. PS refers to phosphatidyl serine micelles. (C) The percentage of released DNA quantified from the agarose gel using the Image Lab ${ }^{\mathrm{TM}}$ software.

\section{DISCUSSION}

The transfection of the well-established, human NT2 or NT2-N cells is widely employed to obtain suitable platforms for the delivery of exogenous proteins into the $\mathrm{CNS}^{3,7,12,13}$. Indeed, the glioma tropism of NT2 cells ${ }^{9}$ makes this undifferentiated cell line an interesting tool to derive new cellular vehicles for clinical glioblastoma therapy. Until now, most of the studies based on genetically engineered NT2 cells rely on the use of viral vectors. However, the development of non-viral transfection strategies to produce stable or transient population of NT2 cells expressing exogenous gene products has distinct advantages, especially if they are subsequently grafted into animals' models of human nervous system diseases.

The successful design of non-viral carriers for gene delivery requires a profound understanding of the transfection process, which is a complex multi-step process influenced by several factors. The vector is first bound to the cell membrane followed by internalization through an endocytic route. To avoid lysosomal degradation, the genetic material has to be released from the endosomes into the cytoplasm and target the nucleus to start the transcription process and protein synthesis. ${ }^{30}$. In recent years, many non-viral vectors have been developed, and their efficient transfection has been demonstrated. However, less attention has been paid to the transfection process itself, starting from the binding to the cell membrane until the DNA reaches the nucleus. Regarding the gene delivery to NT2 cells, no works concerning the whole transfection process mediated by lipoplexes, nioplexes or polyplexes have been previously reported. The understanding of how the physicochemical characteristics of the vectors influence their intracellular traffic could lead to the design of new formulations with specific characteristics that could favour an appropriate intracellular pathway to obtain high 
transfection efficiencies. Thus, we have compared in neuronal precursor NT2 cells the transfection efficiency and uptake mechanisms of three different non-viral vectors.

The physicochemical characteristics and the composition of the non-viral vectors influence their interaction with the cell membrane and their intracellular uptake ${ }^{31,35}$. Thus, the characterization of the complexes is essential to understand better their behavior when they are in contact with the cells. The data obtained from lipoplexes based on Lipofectamine (size of $144.1 \mathrm{~nm}$ and zeta potential of $-29.13 \mathrm{mV}$ ) (Fig. 1) is corroborated by other works, where lipoplexes elaborated with Lipofectamine (w/w ratio $4: 1)$ had similar size and zeta potential values $(150 \mathrm{~nm}$ and $-0.4 \mathrm{mV}){ }^{36}$. The lower zeta potential that we obtained could be explained due to the lower w/w (2:1) that we used to elaborate the lipoplexes. Concerning nioplexes and polyplexes, our previous works supported our current results ${ }^{25,28}$.

The transfection efficiency of the three vectors and the EGFP production was analyzed along the time. Our findings revealed that negatively charged lipoplexes exhibited the highest transfection efficiencies and protein expression levels ${ }^{37-39}$, which decreased along the time (Fig. 3 and Fig. 4). Lipofectamine is a well-known transfection agent with high transfection efficiency ${ }^{36}$. Although we did not show significant toxicity signs in NT2 cell line with our in vitro viability assay (Fig. 2), we previously reported the in vitro cytotoxicity of Lipofectamine in other cell lines ${ }^{25}$.Thus, the in vivo application of this reagent has been limited due to its high toxicity compared to other compounds ${ }^{40}$. Our group has previously reported positive results obtained with nioplexes in vitro, ARPE 19 cells, and in vivo ${ }^{25}$. Surprisingly, nioplexes did not exhibit the expected transfection efficiencies in NT2 cells. So, we must consider that transfection efficiency is cell line dependent ${ }^{41}$. As an alternative to lipid-based vectors, low molecular weight, and highly deacetylated chitosan have showed promising results $28,29,42$. Against all predictions, our results indicated that polyplexes were more efficient for the transfection of NT2 cells than nioplexes. Although the transfection efficiency values were lower than the ones obtained with lipoplexes (15\% versus $35 \%$ at $24 \mathrm{~h}$ shown in Fig. 3), the low toxicity of this polymer enhances its possible clinical applications. Moreover, we should consider that the transfection efficiency of chitosan could be enhanced by its conjugation with several compounds ${ }^{43}$. 
In order to understand the differences in the transfection efficiency observed between the vectors, the cellular uptake of the carriers was determined after 1 and 4 hours of incubation (Fig. 5). The time dependent cellular uptake was already described before by Apaolaza et al. They reported that the cellular uptake of solid lipid nanoparticles in ARPE19 and HEK293 increased along the time, obtaining the highest results after $8 \mathrm{~h}$ of incubation ${ }^{44}$. Douglas et al. described that the cellular uptake of alginate-chitosan nanoparticles in 293T, COS7 and $\mathrm{CHO}$ cells reached a plateau by $2 \mathrm{~h}$ post-treatment ${ }^{41}$. As our transfection experiments were stopped after $4 \mathrm{~h}$ of incubation, we decided not to prolong the uptake studies more than $4 \mathrm{~h}$ since our aim was only to compare the cellular uptake of the three formulations. The cellular uptake was clearly influenced by the carrier type. Lipoplexes (negatively charged) entered in almost $70 \%$ of the cells at $4 \mathrm{~h}$ and polyplexes (positively charged) in $30 \%$ of the cells. Although the uptake of positively charged nanoparticles is presumably favored, the evidence of uptake of negatively charged nanoparticles has been reported. Despite the expected unfavorable interaction between the particles and the negatively charged cell membrane ${ }^{45}$, recent work by Gainza et al. has reveled high uptake levels of lipid carriers ($34 \mathrm{mV}$ ) in several cell lines ${ }^{46}$. The uptake of negatively charged lipoplexes could be explained due to the interactions that may exist between the cationic lipids present in lipoplexes formulation and the lipid compounds in the cell membrane. Despite the desirable physicochemical characteristics observed in the nioplexes, $(140 \mathrm{~nm}$ and $+35 \mathrm{mV})$, we unexpectedly found that the cellular uptake of these vectors in NT2 cells was very low (10 $\%$ at 4 h). Mochizuki et al. also reported low cellular uptake results with complexes based on cationic lipids and FITC labeled DNA ${ }^{34}$. By contrast, our research group has preliminary results that indicate that the cellular uptake of these nioplexes is almost $100 \%$ in ARPE19 cells. All these data suggest that it is necessary to investigate the behavior of the formulations in every selected cell lines. Overall, the cellular uptake results showed an apparent correlation respect to the corresponding transfection efficiency.

In order to obtain further information about the transfection process of our carriers and considering the different physicochemical characteristic of the studied vectors, we performed colocalization studies to elucidate if the characteristics of the vectors could influence their uptake mechanism and intracellular traffic. Due to the low cellular uptake of nioplexes, these were discarded for the following experiments. Endocytosis has been postulated as the principal mechanism of entry for non-viral vectors. Regarding nanoparticle uptake, CME and CvME are the most common and studied endocytosis routes 
47. By confocal imaging and colocalization assays (Fig. 6), we concluded that cell entry of lipoplexes $(140 \mathrm{~nm},-29 \mathrm{mV})$ occurred mainly through CME, while polyplexes $(290 \mathrm{~nm}$, $+15 \mathrm{mV}$ ) entered the cell mainly by CvME. However, we did not observe radical differences, indicating that both pathways would be involved in the uptake of the two formulations. Although the data reported in the literature regarding the relationship between nanosizes and endocytic pathways is sometimes inconsistent, according to Rejman et al. internalization of microspheres with diameter $<200 \mathrm{~nm}$ involved clathrin-coated pits, while an increase in size provoked a shift of the mechanism that relies on caveolae-mediated endocytosis ${ }^{48}$. Moreover, the internalization process may be also affected by the components of the vectors. The entry of Lipofectamine based lipoplexes by the CME in a myoblast cell line was previously reported by Billiet et al. ${ }^{36}$. Peng et al. described that chitosan/poly(g-glutamic acid) complexes were internalized by macropynocitosis and caveolae-mediated pathway in HT1080 human fibrosarcoma cell line ${ }^{49}$. The major problem of analyzing the effects of the size in the trafficking process is the high polydispersity of many nanomaterials, as it occurs with our chitosan based polyplexes, where large and small particles coexist and different entry pathways may be involved. The surface characteristics of nanoparticles can also influence their internalization mechanisms. Unlike our results, according to the literature, positively charged vectors predominantly internalize through CME, while negatively charged formulations utilize CvME ${ }^{50}$. Nevertheless, exemptions including negatively charted PLGA nanoparticles that enter the cell through caveolaeindependent pathways and PEI based cationic polyplexes that utilize CvME have also been reported in the literature ${ }^{47,51}$. In addition, we cannot forget that apart from CME and CvME, clathrin- and caveolae- independent endocytosis routes may also take part in the internalization of the nanoparticles ${ }^{35,52}$. It is worth mentioning that depending on the cell line the internalization pathway of a particular complex could vary. Thus, our results should only be considered for the NT2 cell line.

At 4 hours, the highest colocalization for both lipoplexes and polyplexes was observed in the late endosome (Fig. 7) being superior with polyplexes, (0.735) compared to lipoplexes (0.543). Particles that enter via CME are confined within endosomes that will suffer a maturation process involving the compartment acidification that results in late endosomes and finally, lysosomes. Although some authors described the CvME as a route away from lysosomal degradation, recently, it has been postulated that the caveosomes are considered to fuse with normal acidified endosomes, allowing the transfer of material to lysosomes ${ }^{53}$. 
This hypothesis supports our results since the polyplexes that enter the cell mainly via caveolae-mediated pathways were entrapped in the late-endosomes. In addition, the particle transport mechanism (active transport or diffusion) could define the final fate of the complexes. Particles that are actively transported are usually shuttled from endosomes to lysosomes for degradation ${ }^{54}$. Thus, the next step in the transfection process consists in the endosomal escape of the DNA to avoid lysosomal degradation. Several endosomal escape mechanisms are described in the literature, which vary depending on the nanoparticle ${ }^{55}$. A widely used approach consists of the "proton-sponge effect" which involves nanoparticles having a high buffering capacity, as it is the case of cationic polymers such us PEI. We previously described that UOC posse's higher buffering capacity that high molecular weight chitosans ${ }^{56}$. Another mechanism involves the electrostatic interactions between the nanoparticles and the anionic lipids of the endosome membrane, which causes the destabilization of the endosomal membrane allowing the release of the cargo. As an analogue of the endosomal compartment, we elaborated anionic micelles made from PS, according to Mochizuki's et al. protocol ${ }^{34}$. As observed in Fig. 7B and 7C, the contact of the vectors with the PS micelles led to the release of the DNA from the particles. This simulated the ability of the studied formulations to release the DNA once they contact the lipid membrane of the endosome, which is a requisite for an efficient transfection.

The velocity of the internalization process could vary depending on the carrier, especially depending on its size ${ }^{48}$. We observed a difference in the internalization velocity of the two studied vectors that could be related to the differences in their size. The colocalization values that we achieved with lipoplexes and the specific markers at $4 \mathrm{~h}$ and $6 \mathrm{~h}$ were lower compared to the values obtained with polyplexes, which means that at the tested times most of the lipoplexes were not located within the endosomes. Moreover, $6 \mathrm{~h}$ after the addition of the particles to the cells, the FITC-labeled DNA carried by lipoplexes was found in the nucleus while the DNA carried by polyplexes was still located within the late endosomes (Fig.7A). These findings suggested that the internalization process of lipoplexes is a relatively rapid process compared to polyplexes. Rejma et al. described that internalization process of latex beads with $50-100 \mathrm{~nm}$ diameter was faster than the process of $200 \mathrm{~nm}$ particles $^{48}$.

\section{CONCLUSION}


In summary, we have elaborated and characterized three different vectors for pDNA delivery to human neuronal precursor NT2 cells. Their transfection efficiency and cellular uptake were analyzed along the time observing a correlation between both processes. In order to further understand the behavior of the complexes inside the cells, we determined the uptake mechanism of lipoplexes and polyplexes, concluding that they enter the cells mainly via CME and CvME, respectively. Also, at four hours the complexes were localized in the late endosome and were able to release the DNA. Differences in the internalization velocity were observed between lipoplexes and polyplexes. The DNA carried by lipoplexes was localized in the nucleus at six hours while the DNA carried by polyplexes remained in the late endosome. It is hard to draw general conclusions about how to produce complexes with optimal transfection efficiencies. Therefore, it is essential to evaluate and design an appropriate vector for each cell line. According to our results, the cellular uptake of the complexes is a bottleneck in the transfection process of NT2 cells. Overall, this work gives some knowledge about the main aspects that need to be considered for the design and development of novel non-viral vectors to efficiently transfect human neuronal precursor NT2 cells as a first step in the development of a suitable platform for the delivery of exogenous biological agents into the CNS.

\section{Acknowledgements}

This project was partially supported by the University of the Basque Country UPV/EHU (UFI 11/32 and UFI1 1/35), the Basque Government (Department of Education, GIC-12/150 to J.S, University and Research, for the predoctoral BFI-2011-2226 fellowship, and Department of Industry SAIOTEK S-PE13UN193) and the National Council of Science and Technology (CONACYT, Mexico, Reg. 217101). Technical and human support provided by SGIker (UPV/EHU) is gratefully acknowledged. Authors also wish to thank the intellectual and technical assistance from the ICTS "NANBIOSIS", more specifically, by the Drug Formulation Unit (U10) of the CIBER in Bioengineering, Biomaterials \& Nanomedicine (CIBER-BBN) at the University of Basque Country (UPV/EHU).

\section{Conflicts of interest}

The authors confirm that there are no known conflicts of interest associated with this publication and there has been no significant financial support for this work that could have influenced its outcome. 


\section{REFERENCES}

(1) Andrews, P. W. Retinoic acid induces neuronal differentiation of a cloned human embryonal carcinoma cell line in vitro. Dev. Biol. 1984, 103,285-293

(2) Trojanowski, J. Q., Mantione, J. R., Lee, J. H., Seid, D. P., You, T., Inge, L. J. and Lee, V. M. Neurons derived from a human teratocarcinoma cell line establish molecular and structural polarity following transplantation into the rodent brain. Exp. Neurol. 1993, 122,283-294

(3) Trojanowski, J. Q., Kleppner, S. R., Hartley, R. S., Miyazono, M., Fraser, N. W., Kesari, S. and Lee, V. M. Transfectable and transplantable postmitotic human neurons: a potential "platform" for gene therapy of nervous system diseases. Exp. Neurol. 1997, $144,92-97$

(4) Borlongan, C. V., Tajima, Y., Trojanowski, J. Q., Lee, V. M. and Sanberg, P. R. Cerebral ischemia and CNS transplantation: differential effects of grafted fetal rat striatal cells and human neurons derived from a clonal cell line. Neuroreport 1998, 9,3703-3709

(5) Andrews, P. W. From teratocarcinomas to embryonic stem cells. Philos. Trans. $R$. Soc. Lond. B. Biol. Sci. 2002, 357,405-417

(6) Nelson, P. T., Kondziolka, D., Wechsler, L., Goldstein, S., Gebel, J., DeCesare, S., Elder, E. M., Zhang, P. J., Jacobs, A., McGrogan, M., Lee, V. M. and Trojanowski, J. Q. Clonal human (hNT) neuron grafts for stroke therapy: neuropathology in a patient 27 months after implantation. Am. J. Pathol. 2002, 160,1201-1206

(7) Hara, K., Matsukawa, N., Yasuhara, T., Xu, L., Yu, G., Maki, M., Kawase, T., Hess, D. C., Kim, S. U. and Borlongan, C. V. Transplantation of post-mitotic human neuroteratocarcinoma-overexpressing Nurr1 cells provides therapeutic benefits in experimental stroke: in vitro evidence of expedited neuronal differentiation and GDNF secretion. J. Neurosci. Res. 2007, 85,1240-1251

(8) Newman, M. B., Misiuta, I., Willing, A. E., Zigova, T., Karl, R. C., Borlongan, C. V. and Sanberg, P. R. Tumorigenicity issues of embryonic carcinoma-derived stem cells: relevance to surgical trials using NT2 and hNT neural cells. Stem Cells Dev. 2005, $14,29-43$

(9) Zhao, Y. and Wang, S. Human NT2 neural precursor-derived tumor-infiltrating cells as delivery vehicles for treatment of glioblastoma. Hum. Gene Ther. 2010, 21,683-694

(10) Aboody, K. S., Brown, A., Rainov, N. G., Bower, K. A., Liu, S., Yang, W., Small, J. E., Herrlinger, U., Ourednik, V., Black, P. M., Breakefield, X. O. and Snyder, E. Y. Neural stem cells display extensive tropism for pathology in adult brain: evidence from intracranial gliomas. Proc. Natl. Acad. Sci. U. S. A. 2000, 97,12846-12851

(11) Benedetti, S., Pirola, B., Pollo, B., Magrassi, L., Bruzzone, M. G., Rigamonti, D., Galli, R., Selleri, S., Di Meco, F., De Fraja, C., Vescovi, A., Cattaneo, E. and 
Finocchiaro, G. Gene therapy of experimental brain tumors using neural progenitor cells. Nat. Med. 2000, 6,447-450

(12) Pleasure, S. J., Page, C. and Lee, V. M. Pure, postmitotic, polarized human neurons derived from NTera 2 cells provide a system for expressing exogenous proteins in terminally differentiated neurons. J. Neurosci. 1992, 12,1802-1815

(13) Watson, D. J., Longhi, L., Lee, E. B., Fulp, C. T., Fujimoto, S., Royo, N. C., Passini, M. A., Trojanowski, J. Q., Lee, V. M., McIntosh, T. K. and Wolfe, J. H. Genetically modified NT2N human neuronal cells mediate long-term gene expression as CNS grafts in vivo and improve functional cognitive outcome following experimental traumatic brain injury. J. Neuropathol. Exp. Neurol. 2003, 62,368-380

(14) Kofler, P., Wiesenhofer, B., Rehrl, C., Baier, G., Stockhammer, G. and Humpel, C. Liposome-mediated gene transfer into established CNS cell lines, primary glial cells, and in vivo. Cell Transplant. 1998, 7,175-185

(15) Nikcevic, G., Kovacevic-Grujicic, N. and Stevanovic, M. Improved transfection efficiency of cultured human cells. Cell Biol. Int. 2003, 27,735-737

(16) Wang, Y., Miao, L., Satterlee, A. and Huang, L. Delivery of oligonucleotides with lipid nanoparticles. Adv. Drug Deliv. Rev. 2015,

(17) Namvar, A., Bolhassani, A., Khairkhah, N. and Motevalli, F. Physicochemical properties of polymers: An important system to overcome the cell barriers in gene transfection. Biopolymers 2015, 103,363-375

(18) Dewey, R. A., Morrissey, G., Cowsill, C. M., Stone, D., Bolognani, F., Dodd, N. J., Southgate, T. D., Klatzmann, D., Lassmann, H., Castro, M. G. and Lowenstein, P. R. Chronic brain inflammation and persistent herpes simplex virus 1 thymidine kinase expression in survivors of syngeneic glioma treated by adenovirus-mediated gene therapy: implications for clinical trials. Nat. Med. 1999, 5,1256-1263

(19) Fox, J. L. Gene-therapy death prompts broad civil lawsuit. Nat. Biotechnol. 2000, 18,1136

(20) Rothe, M., Modlich, U. and Schambach, A. Biosafety challenges for use of lentiviral vectors in gene therapy. Curr. Gene Ther. 2013, 13,453-468

(21) Li, S. D. and Huang, L. Gene therapy progress and prospects: non-viral gene therapy by systemic delivery. Gene Ther. 2006, 13,1313-1319

(22) Pezzoli, D., Chiesa, R., De Nardo, L. and Candiani, G. We still have a long way to go to effectively deliver genes! J. Appl. Biomater. Funct. Mater. 2012, 10,82-91

(23) Sen, K. and Mandal, M. Second generation liposomal cancer therapeutics: transition from laboratory to clinic. Int. J. Pharm. 2013, 448,28-43 
(24) Dalby, B., Cates, S., Harris, A., Ohki, E. C., Tilkins, M. L., Price, P. J. and Ciccarone, V. C. Advanced transfection with Lipofectamine 2000 reagent: primary neurons, siRNA, and high-throughput applications. Methods 2004, 33,95-103

(25) Puras, G., Mashal, M., Zarate, J., Agirre, M., Ojeda, E., Grijalvo, S., Eritja, R., Diaz-Tahoces, A., Martinez Navarrete, G., Aviles-Trigueros, M., Fernandez, E. and Pedraz, J. L. A novel cationic niosome formulation for gene delivery to the retina. $J$. Control. Release 2014, 174,27-36

(26) Ojeda, E., Puras, G., Agirre, M., Zarate, J., Grijalvo, S., Pons, R., Eritja, R., Martinez-Navarrete, G., Soto-Sanchez, C., Fernandez, E. and Pedraz, J. L. Niosomes based on synthetic cationic lipids for gene delivery: the influence of polar head-groups on the transfection efficiency in HEK-293, ARPE-19 and MSC-D1 cells. Org. Biomol. Chem. 2015, 13,1068-1081

(27) Buschmann, M. D., Merzouki, A., Lavertu, M., Thibault, M., Jean, M. and Darras, V. Chitosans for delivery of nucleic acids. Adv. Drug Deliv. Rev. 2013, 65,1234-1270

(28) Puras, G., Zarate, J., Aceves, M., Murua, A., Díaz, A. R., Avilés-Triguero, M., Fernández, E. and Pedraz, J. L. Low molecular weight oligochitosans for non-viral retinal gene therapy.. Eur J Pharm Biopharm 2012,

(29) Agirre, M., Zarate, J., Ojeda, E., Puras, G., Rojas, L. A., Alemany, R. and Pedraz, J. L. Delivery of an adenovirus vector plasmid by ultrapure oligochitosan based polyplexes. Int. J. Pharm. 2015, 479,312-319

(30) Wang, T., Upponi, J. R. and Torchilin, V. P. Design of multifunctional non-viral gene vectors to overcome physiological barriers: Dilemmas and strategies. Int. J.

Pharm. 2012, 427,3-20

(31) Hillaireau, H. and Couvreur, P. Nanocarriers' entry into the cell: relevance to drug delivery. Cell Mol. Life Sci. 2009, 66,2873-2896

(32) Grijalvo, S., Ocampo, S. M., Perales, J. C. and Eritja, R. Synthesis of lipidoligonucleotide conjugates for RNA interference studies. Chem. Biodivers 2011, 8,287299

(33) Zinchuk, V., Zinchuk, O. and Okada, T. Quantitative colocalization analysis of multicolor confocal immunofluorescence microscopy images: pushing pixels to explore biological phenomena. Acta Histochem. Cytochem. 2007, 40,101-111

(34) Mochizuki, S., Kanegae, N., Nishina, K., Kamikawa, Y., Koiwai, K., Masunaga, H. and Sakurai, K. The role of the helper lipid dioleoylphosphatidylethanolamine (DOPE) for DNA transfection cooperating with a cationic lipid bearing ethylenediamine.

Biochim. Biophys. Acta 2013, 1828,412-418

(35) Pozzi, D., Marchini, C., Cardarelli, F., Salomone, F., Coppola, S., Montani, M., Zabaleta, M. E., Digman, M. A., Gratton, E., Colapicchioni, V. and Caracciolo, G. Mechanistic evaluation of the transfection barriers involved in lipid-mediated gene 
delivery: interplay between nanostructure and composition. Biochim. Biophys. Acta 2014, 1838,957-967

(36) Billiet, L., Gomez, J. P., Berchel, M., Jaffres, P. A., Le Gall, T., Montier, T., Bertrand, E., Cheradame, H., Guegan, P., Mevel, M., Pitard, B., Benvegnu, T., Lehn, P., Pichon, C. and Midoux, P. Gene transfer by chemical vectors, and endocytosis routes of polyplexes, lipoplexes and lipopolyplexes in a myoblast cell line. Biomaterials $\mathbf{2 0 1 2}$, 33,2980-2990

(37) Sun, P., Zhong, M., Shi, X. and Li, Z. Anionic LPD complexes for gene delivery to macrophage: preparation, characterization and transfection in vitro. J. Drug Target.

2008, 16,668-678

(38) Tagalakis, A. D., Lee do, H. D., Bienemann, A. S., Zhou, H., Munye, M. M., Saraiva, L., McCarthy, D., Du, Z., Vink, C. A., Maeshima, R., White, E. A., Gustafsson, K. and Hart, S. L. Multifunctional, self-assembling anionic peptide-lipid nanocomplexes for targeted siRNA delivery. Biomaterials 2014, 35,8406-8415

(39) Zhang, W., Peng, F., Zhou, T., Huang, Y., Zhang, L., Ye, P., Lu, M., Yang, G., Gai, Y., Yang, T., Ma, X. and Xiang, G. Targeted delivery of chemically modified antimiR-221 to hepatocellular carcinoma with negatively charged liposomes. Int. J.

Nanomedicine 2015, 10,4825-4836

(40) Yang, Z., Jiang, Z., Cao, Z., Zhang, C., Gao, D., Luo, X., Zhang, X., Luo, H., Jiang, Q. and Liu, J. Multifunctional non-viral gene vectors with enhanced stability, improved cellular and nuclear uptake capability, and increased transfection efficiency. Nanoscale 2014, 6,10193-10206

(41) Douglas, K. L., Piccirillo, C. A. and Tabrizian, M. Cell line-dependent internalization pathways and intracellular trafficking determine transfection efficiency of nanoparticle vectors. European Journal of Pharmaceutics and Biopharmaceutics 2008, 68,676-687

(42) Klausner, E. A., Zhang, Z., Chapman, R. L., Multack, R. F. and Volin, M. V. Ultrapure chitosan oligomers as carriers for corneal gene transfer. Biomaterials 2010, $31,1814-1820$

(43) Han, L., Tang, C. and Yin, C. Enhanced antitumor efficacies of multifunctional nanocomplexes through knocking down the barriers for siRNA delivery. Biomaterials 2015, 44,111-121

(44) Apaolaza, P. S., Delgado, D., del Pozo-Rodriguez, A., Gascon, A. R. and Solinis, M. A. A novel gene therapy vector based on hyaluronic acid and solid lipid nanoparticles for ocular diseases. Int. J. Pharm. 2014, 465,413-426

(45) Patil, S., Sandberg, A., Heckert, E., Self, W. and Seal, S. Protein adsorption and cellular uptake of cerium oxide nanoparticles as a function of zeta potential.

Biomaterials 2007, 28,4600-4607 
(46) Gainza, G., Pastor, M., Aguirre, J. J., Villullas, S., Pedraz, J. L., Hernandez, R. M. and Igartua, M. A novel strategy for the treatment of chronic wounds based on the topical administration of rhEGF-loaded lipid nanoparticles: In vitro bioactivity and in vivo effectiveness in healing-impaired db/db mice. J. Control. Release 2014, 185,51-61

(47) Rejman, J., Bragonzi, A. and Conese, M. Role of clathrin- and caveolae-mediated endocytosis in gene transfer mediated by lipo- and polyplexes. Mol. Ther. 2005, 12,468474

(48) Rejman, J., Oberle, V., Zuhorn, I. S. and Hoekstra, D. Size-dependent internalization of particles via the pathways of clathrin- and caveolae-mediated endocytosis. Biochem. J. 2004, 377,159-169

(49) Peng, S. F., Tseng, M. T., Ho, Y. C., Wei, M. C., Liao, Z. X. and Sung, H. W. Mechanisms of cellular uptake and intracellular trafficking with chitosan/DNA/poly(gamma-glutamic acid) complexes as a gene delivery vector. Biomaterials 2011, 32,239-248

(50) Sahay, G., Alakhova, D. Y. and Kabanov, A. V. Endocytosis of nanomedicines. J. Control. Release 2010, 145,182-195

(51) Qaddoumi, M. G., Ueda, H., Yang, J., Davda, J., Labhasetwar, V. and Lee, V. H. The characteristics and mechanisms of uptake of PLGA nanoparticles in rabbit conjunctival epithelial cell layers. Pharm. Res. 2004, 21,641-648

(52) Ruiz de Garibay, A. P., Solinis Aspiazu, M. A., Rodriguez Gascon, A., Ganjian, H. and Fuchs, R. Role of endocytic uptake in transfection efficiency of solid lipid nanoparticles-based nonviral vectors. J. Gene Med. 2013, 15,427-440

(53) Iversen, T., Skotland, T. and Sandvig, K. Endocytosis and intracellular transport of nanoparticles: Present knowledge and need for future studies. Nano Today 2011, 6,176185

(54) Pozzi, D., Marchini, C., Cardarelli, F., Rossetta, A., Colapicchioni, V., Amici, A., Montani, M., Motta, S., Brocca, P., Cantu, L. and Caracciolo, G. Mechanistic understanding of gene delivery mediated by highly efficient multicomponent envelopetype nanoparticle systems. Mol. Pharm. 2013, 10,4654-4665

(55) Varkouhi, A. K., Scholte, M., Storm, G. and Haisma, H. J. Endosomal escape pathways for delivery of biologicals. J. Controlled Release 2011, 151,220-228

(56) Agirre, M., Zarate, J., Puras, G., Ojeda, E. and Pedraz, J. L. Improving transfection efficiency of ultrapure oligochitosan/DNA polyplexes by medium acidification. Drug Deliv. 2014, 